\title{
Adjunctive Effect of Doxycycline with Conventional Periodontal Therapy on Glycemic Level for Chronic Periodontitis with Type 2 Diabetes Mellitus Subjects
}

\author{
Abhaya C Das ${ }^{1}$, Swarga J Das ${ }^{2}$, Saurav Panda ${ }^{3}$, Dipti Sharma ${ }^{4}$, Silvio Taschieri ${ }^{5}$, Massimo D Fabbro ${ }^{6}$
}

\begin{abstract}
Aims: This study aimed to assess the use of doxycycline in adjunct to periodontal therapy on the glycemic levels for chronic periodontitis patients with type 2 diabetes mellitus (DM).

Materials and methods: Fifty-one diabetic subjects with chronic periodontitis were selected and randomly assigned into 3 groups with 17 subjects each. Scaling and root planing (SRP) was done in group I, SRP and doxycycline was given in group II, and group III did not receive any periodontal treatment till 3 months. Probing pocket depth (PPD), clinical attachment level (CAL), plaque index (PI), gingival index (GI), and metabolic parameters were evaluated at baseline (day 0) and after 3 months (day 90). The statistical analysis was carried out using SPSS 17.0 software with significance fixed at $95 \% \mathrm{Cl}(p<0.05)$.

Results: The mean difference between baseline and day 90 for all periodontal parameters was significantly higher $(p<0.01)$ in group I and group II compared to control (group III). The metabolic parameters such as fasting plasma glucose (FPG), 2-hour postprandial plasma glucose (PPG), and glycated hemoglobin ( $\mathrm{HbA} 1 \mathrm{c} \%$ ) level were reduced in groups I and II compared to group III; however, only $\mathrm{HbA1} \%$ values were found significantly reduced $(p<0.01)$ at day 90 . Group II showed significantly better metabolic parameters than group I at day 90 .

Conclusion: The adjunct of doxycycline to conventional periodontal therapy provides additional benefit in reducing glycemic level and improves periodontal health.

Clinical significance: The prevalence of diabetes as well as periodontitis is increasing nowadays in the world. With treatment of periodontitis, it is found that there is reduction of glycemic level in diabetes. So it is an alert to health professionals about the relation of diabetes and periodontitis and so that they conduct a multidisciplinary treatment.
\end{abstract}

Keywords: Diabetes, Doxycycline, Glycated hemoglobin, Periodontitis, Root planing, Scaling.

The Journal of Contemporary Dental Practice (2019): 10.5005/jp-journals-10024-2722

\section{INTRODUCTION}

Periodontitis is an inflammatory condition affecting both soft and hard parts of periodontium, with multifactorial etiology. Periodontitis is considered to be the major cause of tooth loss in adults and has also been claimed to affect the systemic conditions of the individual. ${ }^{2}$ The inflammatory mediators released in chronic periodontitis affects the general health. ${ }^{3}$ The pathophysiology of various inflammatory systemic conditions like rheumatic arthritis, cardiovascular diseases, and diabetes mellitus (DM), etc., is considered to be synergistically influenced by such inflammatory mediators. ${ }^{3}$ Various studies were carried out to establish such association between the incidence of periodontitis and its effect on patient's systemic conditions. Diabetes mellitus is one such chronic systemic condition, which is adversely affected in presence of these inflammatory mediators. ${ }^{4}$

Diabetes mellitus (also known as noninsulin dependent diabetes or type $2 \mathrm{DM}$ ) is a chronic disease caused by a defect in the secretion of pancreatic insulin and/or an insensitivity of target tissues to its action leading to hyperglycemia, which is also noncommunicable and is considered as one of the major health conditions affecting public general health globally. ${ }^{4,5}$ The association between diabetes and periodontitis is generally considered to be as a doubleedge sword. The diabetes affects the onset and progression of periodontitis, and conversely, the periodontitis worsens the diabetic status of an individual by altering their glycemic control. ${ }^{6,7}$ It is established that the prevalence of periodontitis is two-three times higher in diabetic patients. ${ }^{8}$ Diabetes mellitus increases the 1,30partment of Periodontics and Oral Implantology, Institute of Dental Sciences, Siksha ' $O$ ' Anusandhan (Deemed to be university), Bhubaneswar, Odisha, India

${ }^{2}$ Department of Periodontics and Oral Implantology, Regional Dental College, Guwahati, Assam, India

${ }^{4}$ Department of Endocrinology, Gauhati Medical College, Guwahati, Assam, India

5,6Department of Biomedical, Surgical and Dental Sciences, IRCCS Galeazzi Orthopedic Institute, Milan, Lombardia, Italy

Corresponding Author: Abhaya C Das, Department of Periodontics and Oral Implantology, Institute of Dental Sciences, Siksha ' $O$ ' Anusandhan (Deemed to be university), Bhubaneswar, Odisha, India, Phone: +91 9437088379, e-mail: drabhaya2011@gmail.com

How to cite this article: Das AC, Das SJ, Panda S, et al. Adjunctive Effect of Doxycycline with Conventional Periodontal Therapy on Glycemic Level for Chronic Periodontitis with Type 2 Diabetes Mellitus Subjects. J Contemp Dent Pract 2019;20(12):1417-1423.

Source of support: Nil

Conflict of interest: None

severity of periodontitis compared to patients without diabetes. ${ }^{9}$ And also the periodontitis is considered to be one of the diabetic complications. $^{10,11}$

Conversely, there is also evidence to indicate the adverse effect of periodontitis on glycemic control in diabetics. Elevated levels of several

o The Author(s). 2019 Open Access This article is distributed under the terms of the Creative Commons Attribution 4.0 International License (https://creativecommons. org/licenses/by-nc/4.0/), which permits unrestricted use, distribution, and non-commercial reproduction in any medium, provided you give appropriate credit to the original author(s) and the source, provide a link to the Creative Commons license, and indicate if changes were made. The Creative Commons Public Domain Dedication waiver (http://creativecommons.org/publicdomain/zero/1.0/) applies to the data made available in this article, unless otherwise stated. 
proinflammatory cytokines [tumor necrosis factor alpha (TNF-a), IL-6] are seen in periodontitis. ${ }^{12-14}$ The alteration in monocyte/ macrophage phenotype in cases of DM leads to increased production of these inflammatory cytokines, which further worsen the insulin resistance and, thereby, aggravate poor glycemic control. ${ }^{15}$

Considering these various mechanisms that promote insulin resistance, it is clear that a chronic systemic inflammatory state induced by periodontal disease may contribute further to insulin resistance in individuals with DM through a "feed-forward" mechanism. ${ }^{16}$ This explains the mechanisms of poor glycemic control in diabetics with periodontal disease. ${ }^{17}$

It is believed that in patients with type $2 \mathrm{DM}$, antimicrobial periodontal therapy can cause a significant reduction of $\mathrm{HbA1c}$ value. ${ }^{18}$ It is also found that SRP can improve the glycemic control in patients with type 2 DM with or without adjunctive systemic doxycycline therapy. ${ }^{19}$ According to a recent finding, diabetic patients with chronic periodontitis treated with periodontal treatment and topical antibiotics can improve glycemic control and elevate serum adiponectin with improvement of periodontal status in type 2 diabetic patients. ${ }^{20}$

Doxycycline, which belongs to tetracycline group of antibiotics, is an inexpensive, well-tolerated, broad spectrum antibiotic with an array of additional benefits. Doxycycline is proved to have high sulcular availability concentration when administered systemically. ${ }^{21}$ Further, it demonstrates an inhibitory effect on matrix metallo-proteinases which induces release of various inflammatory mediators. ${ }^{22}$ Moreover, doxycycline also have an inhibitory effect on protein glycation, which is essential for production advanced glycation end products (AGE) and deposition. ${ }^{23}$

This study aimed at evaluating the effect of using systemically administered doxycycline at its recommended dosage, as an adjunct to the conventional periodontal therapy, by assessing the glycemic levels, in treatment of chronic periodontitis patients with type $2 \mathrm{DM}$.

\section{Materials and Methods}

The present study was a prospective, randomized, parallel arm, double-centered clinical trial, which was carried out in the Department of Periodontics, Regional Dental College and Hospital, Guwahati, India in collaboration with the Department of Endocrinology, Guwahati Medical College and Hospital, Guwahati, India. The study was carried out in accordance to the ethical guidelines of Helsinki declaration of 1975, as revised in 2000. The Ethical Committee of Regional Dental College, Guwahati, approved the study with IHEC No. RDC/29/2009/1830 dated 23rd March, 2009. The study was performed from February 2009 to September 2010. The subjects were selected on the basis of the following criteria.

\section{Inclusion Criteria}

- Subjects with type 2 DM.

- Diabetics presented with moderate to severe periodontitis (where $30 \%$ or more of the teeth have $\geq 4 \mathrm{~mm}$ clinical attachment loss).

- Subjects $\geq 30$ years of age regardless of gender.

- Subjects with no evidence of other oral and systemic diseases.

- Subjects under treatment of an endocrinologist.

\section{Exclusion Criteria}

- Subjects with uncontrolled DM.

- Subjects who have undergone periodontal therapy during last 6 months.
- Subjects administered antibiotic during last 3 months.

- Subjects with $<20$ natural teeth.

- Subjects allergic to tetracycline and its derivatives.

- Pregnant and lactating mothers.

- Persons consuming any form of tobacco.

A total of 1,000 subjects were screened to select 80 subjects having type $2 \mathrm{DM}$ with periodontitis. Subsequently, 51 subjects were selected for inclusion into the study. Thorough medical history along with the diabetes record of the subjects was obtained in detail. The concerned endocrinologist was well-informed regarding the study design. Subjects were explained the entire procedure in detail and were included in the study after signing an informed consent form.

No change in the medication or diet was made for the subjects. None of the subjects received any additional guidance regarding the control of their diabetic status. A sample size of at-least 15 patients in each group was estimated to achieve $90 \%$ power to detect mean difference between the groups $(p<0.05)$.

The subjects were randomly categorized into three groups by single investigator (ACD) using a block randomization. The groups were named as I, II, and III (control). The subjects were not blinded with respect to treatment administered. After oral examination, the teeth with poor prognosis were extracted. Subjects taking antibiotics after extraction were included in the study after a period of 3 months.

All subjects underwent periodontal examination by a single examiner [Abhaya C Das (ACD)]. Periodontal status was assessed using PPD, $\mathrm{CAL}, \mathrm{Pl}^{24}$ and $\mathrm{Gl} .{ }^{25}$ The metabolic parameters considered were FPG, PPG, and $\mathrm{HbA} 1 \mathrm{c} \%$ level.

The subjects in group I received oral hygiene instructions and full mouth SRP, while the subjects in group II received doxycycline (DOXT, Dr Reddy's Lab. Ltd, Hyderabad, India) (total dose 1,600 mg in equally divided 16 doses, start as $100 \mathrm{mg}$ BD followed by OD for 14 days $)^{26}$ in addition to the same therapy as that of group I. The group III received no treatment that served as control. All the control group subjects were treated with required periodontal intervention after the final assessment of study parameters after 3 months.

All the periodontal and metabolic parameters were recorded on day 0 and 90 . The data were then analyzed statistically using SPSS version 15 (IBM, Chicago, USA). The normality of the data distributions was assessed by means of the D'Agostino and Pearson omnibus normality test. Paired " $t$ " test was used to compare the various parameters on day 0 and 90 within the same group, while Student's unpaired " $t$ " test was used to compare the parameters between two groups. $p$ value less than 0.05 was considered as statistically significant.

\section{Results}

Out of 1,000 consecutive subjects screened, 80 subjects were selected for the study. Based on the inclusion criteria, 29 subjects were excluded ( 16 due to uncontrolled diabetes and 13 due to less number of teeth present). Finally, 51 subjects ( 30 males and 21 females), having a mean age of $45.92 \pm 7.88$ years (range 30-65 years), fulfilled all the criteria to be included as shown in Table 1. After randomization, 17 subjects were assigned to each group. A flow diagram representing the participants throughout the study is shown in Flowchart 1.

As shown in Table 2, on day 0, the mean PI was $1.99 \pm 0.43$ in group I and decreased by $47.3 \%$ on day 90 (1.04 \pm 0.28$)$. This difference was found to be statistically highly significant $(p<0.01)$. 
Similarly, the mean difference in PI in group II between day 90 and 0 was $1.33(53.20 \%)$ and was statistically very highly significant $(p<0.001)$. On the contrary, the PI in group III was found to be increased by 0.06 (2.46\%) from day 0 to 90 , though not statistically significant $(p>0.05)$.

The $\mathrm{Gl}$ in group I decreased by $45.0 \%$ on day 90 compared to day 0 , which was found to be statistically very highly significant $(p<0.001)$. Similarly, the reduction in Gl in group II between day 90 and 0 was $46.08 \%$ and statistically very highly significant $(p<0.001)$. In contrast, the $\mathrm{Gl}$ in group III was found to be increased by $0.03(2.46 \%)$ from day 0 to 90 , though not statistically significant ( $p>0.05)$ as shown in Table 2.

As shown in Table 2, the mean PPD on day 0 was $3.08 \pm 0.30$ in group I and decreased by $24.67 \%$ on day 90 to $2.32 \pm 0.28$. This difference was found to be statistically very highly significant $(p<0.001)$. Similarly, the mean difference in PPD in group II between day 90 and 0 was 1.01 (30.51\%) and was statistically very highly significant $(p<0.001)$. On the contrary, the PPD in group III was

Table 1: Baseline demographic characteristics of subjects who completed the study

\begin{tabular}{lclr}
\hline Subjects & $\begin{array}{l}\text { Group I } \\
\text { (SRP) }\end{array}$ & $\begin{array}{l}\text { Group II } \\
\text { (SRP +Doxy) }\end{array}$ & $\begin{array}{r}\text { Group III } \\
\text { (control) }\end{array}$ \\
\hline Gender & & & $6(35)$ \\
Female (\%) & $7(41)$ & $9(53)$ & $11(65)$ \\
Male (\%) & $10(59)$ & $8(47)$ & $40 \pm 12$ \\
Age (years) & & & \\
Mean \pm SD & $38 \pm 11$ & $42 \pm 13$ & 4 \\
\hline
\end{tabular}

found to be increased by 0.10 from day 0 to 90 (2.53\%), though not statistically significant $(p>0.05)$.

The CAL was reduced by 0.73 (19.26\%) and $0.93 \mathrm{~mm}(24.73 \%)$ on day 90 compared to day 0 in group I and II, respectively, which were found to be very highly significant statistically $(p<0.001)$. In contrast, CAL in group III was increased by $0.07 \mathrm{~mm}$ on day 90 from day 0 , though not statistically significant $(p>0.05)$.

Intergroup comparison between the groups II and I revealed no statistically significant difference in the periodontal parameters ( $p>0.05)$, except in $\mathrm{PI}(p<0.01)$. Again, the differences between the groups II and III, and between the groups I and III, and significant differences were observed in all the periodontal parameters $(p<0.01)$.

As shown in Table 3, on day 0 , in group I, the mean $\mathrm{HbA} 1 \mathrm{c}$ was $7.58 \pm 0.89$, which was reduced by $0.61 \%$ on day 90 to $6.97 \pm 0.86$, though the difference was not significant statistically $(p=0.14)$. Similarly, the mean difference in $\mathrm{HbA1c}$ in group II between days 90 and 0 was 0.93 and was statistically very highly significant $(p<0.001)$. On the contrary, the HbA1c in group III was found to be increased by 0.06 from days 0 to 90 , though not statistically significant $(p>0.05)$.

The FPG was reduced by 7.82 and $16.06 \mathrm{mg} / \mathrm{dL}$ on day 90 compared to that of day 0 in groups I and II, respectively. Again, in group III, it was increased by $2.83 \mathrm{mg} / \mathrm{dL}$. However, these differences within the groups were not found significant statistically $(p>0.05)$ as shown in Table 3.

The PPG was reduced by 15.64 and $24.47 \mathrm{mg} / \mathrm{dL}$ from days 0 to 90 in groups I and II, respectively. Again, in group III, it was increased by $2.36 \mathrm{mg} / \mathrm{dL}$ (Table 3). However, these differences within the groups were not found statistically significant $(p>0.05)$.

Flowchart 1: A CONSORT flowchart representing the participants throughout the study

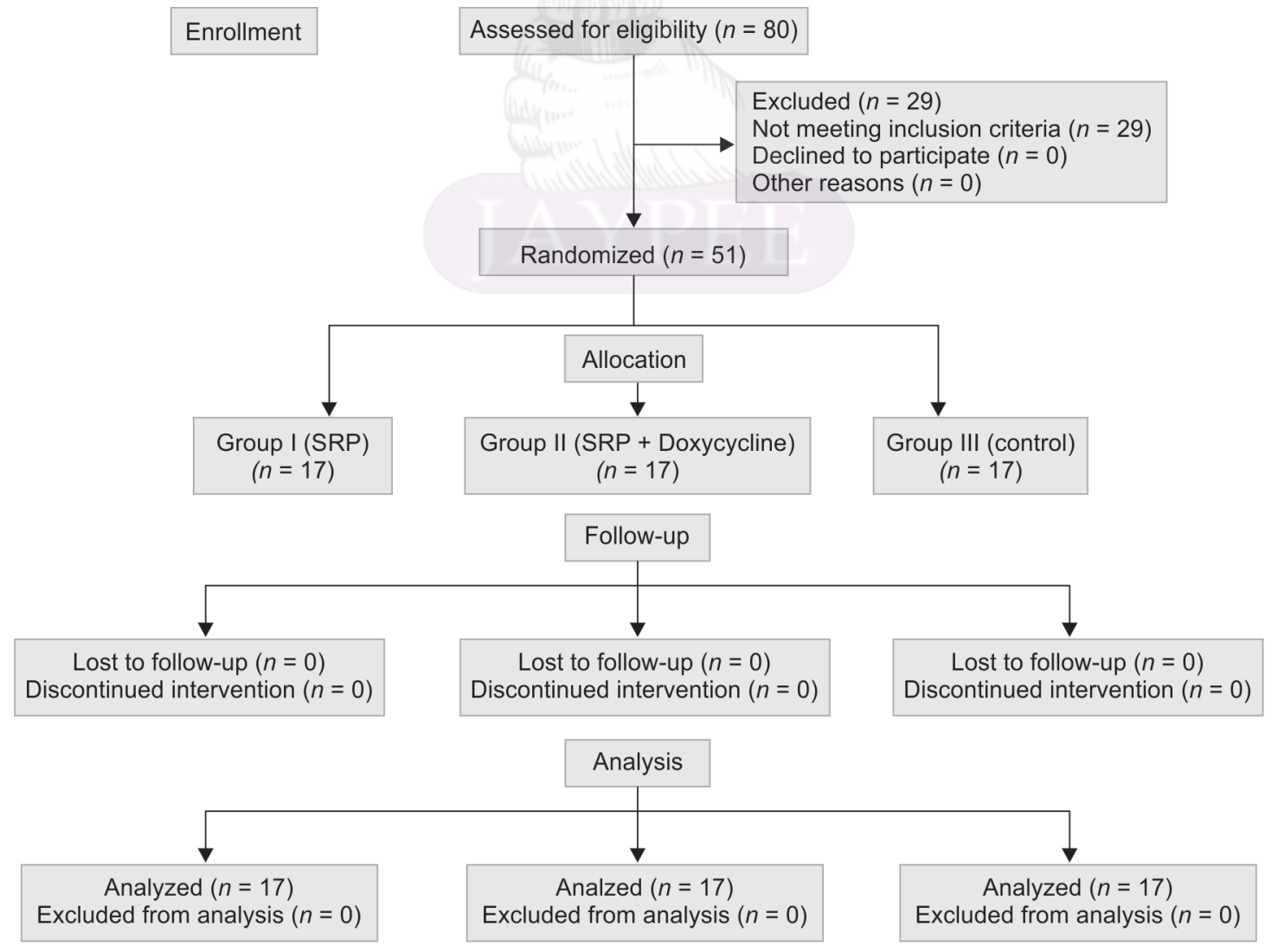


Table 2: Comparison of periodontal parameters in intragroup and intergroup

\begin{tabular}{cllll}
\hline & $P I$ & $G l$ & $P P D(\mathrm{~mm})$ & $C A L(\mathrm{~mm})$ \\
\hline Group I & & & & \\
Day 0 & $1.99 \pm 0.43$ & $1.80 \pm 0.39$ & $3.08 \pm 0.30$ & $3.79 \pm 0.40$ \\
Day 90 & $1.04 \pm 0.28$ & $0.99 \pm 0.28$ & $2.32 \pm 0.28$ & $3.06 \pm 0.42$ \\
$\Delta^{\mathrm{a}}$ & 0.95 & 0.81 & 0.76 & 0.73 \\
$p$ value & $<0.001^{\mathrm{b}}$ & $<0.001^{\mathrm{b}}$ & $<0.001^{\mathrm{b}}$ & $<0.001^{\mathrm{b}}$ \\
Group II & & & & \\
Day 0 & $2.50 \pm 0.42$ & $2.04 \pm 0.33$ & $3.31 \pm 0.62$ & $3.76 \pm 0.66$ \\
Day 90 & $1.17 \pm 0.22$ & $1.10 \pm 0.21$ & $2.30 \pm 0.45$ & $2.83 \pm 0.52$ \\
$\Delta^{\mathrm{a}}$ & 1.33 & 0.94 & 1.01 & 0.93 \\
$p$ value & $<0.001^{\mathrm{b}}$ & $<0.001^{\mathrm{b}}$ & $<0.001^{\mathrm{b}}$ & $<0.001^{\mathrm{b}}$ \\
Group III & & & & \\
Day 0 & $2.37 \pm 0.54$ & $1.95 \pm 0.42$ & $3.42 \pm 0.49$ & $3.84 \pm 0.50$ \\
Day 90 & $2.43 \pm 0.51$ & $1.98 \pm 0.41$ & $3.52 \pm 0.49$ & $3.91 \pm 0.49$ \\
$\Delta^{\mathrm{a}}$ & -0.06 & -0.03 & -0.10 & -0.07 \\
$p$ value & $0.74^{\mathrm{c}}$ & $0.78^{\mathrm{c}}$ & $0.58^{\mathrm{c}}$ & $0.68^{\mathrm{c}}$ \\
$\Delta$ (Dox vs & $0.38^{\mathrm{b}}$ & $0.13^{\mathrm{c}}$ & $0.25^{\mathrm{c}}$ & $0.20^{\mathrm{c}}$ \\
SRP) & & & & \\
$\Delta$ (Dox vs & $1.27^{\mathrm{b}}$ & $0.91^{\mathrm{b}}$ & $0.91^{\mathrm{b}}$ & $0.86^{\mathrm{b}}$ \\
Non) & & & & \\
$\Delta$ (SRP vs & $0.89^{\mathrm{b}}$ & $0.78^{\mathrm{b}}$ & $0.66^{\mathrm{b}}$ & $0.66^{\mathrm{b}}$ \\
Non) & & & & \\
\hline Values are & & & &
\end{tabular}

Values are presented as mean \pm standard deviation

$\mathrm{PI}$, plaque index; $\mathrm{Gl}$, gingival index; $\mathrm{PPD}$, probing pocket depth; $\mathrm{CAL}$, clinical attachment level

${ }^{\mathrm{b}}$ Statistically significant difference

'Not statistically significant difference

$\Delta^{\mathrm{a}}$ : changes in-between day 90 and day 0

$p$ value: comparison between day 90 and day 0

$\Delta$ (Dox vs SRP): changes in mean differences (day 90 vs day 0 ) between group II and group I

$\Delta$ (Dox vs Non): changes in mean differences (day 90 vs day 0 ) between group II and group III

$\Delta$ (SRP vs Non): changes in mean differences (day 90 vs day 0 ) between group I and group III

Intergroup comparison among the groups (II vs I; II vs III; and I vs III) revealed a highly statistically significant difference in all the metabolic parameters $(p>0.01)$.

\section{Discussion}

Diabetes mellitus and periodontal diseases are thought to be associated biologically. Various possible mechanisms have been proposed regarding their influence on each other, ${ }^{12,14-16,27-31}$ and also a high incidence and severity of periodontal disease is reported in diabetics compared to that of nondiabetics. ${ }^{32-34}$ Similarly, improvement in the glycemic level following periodontal therapy has also been reported in various studies. ${ }^{18,35-43}$ In contrast, few other studies failed to determine any positive effect of periodontal therapy on glycemic level. ${ }^{44-48}$ Thus, the effect of periodontal therapy on glycemic level remains questionable.

For the present study, subjects with type 2 DM having chronic periodontitis were selected, because both type $2 \mathrm{DM}$ and chronic periodontitis are highly prevalent among the adults; and type 2 DM has shown a spectacular increase in the past few decades as infections including periodontitis results in increased insulin resistance. ${ }^{12,14,31}$ Subjects with type 1 DM were not selected, because
Table 3: Comparison of metabolic parameters in intragroup and intergroup

\begin{tabular}{llll}
\hline & $H b A 1 c(\%)$ & $F P G(\mathrm{mg} / \mathrm{dL})$ & $P P G(\mathrm{mg} / \mathrm{dL})$ \\
\hline Group I & & & \\
Day 0 & $7.58 \pm 0.89$ & $155.06 \pm 30.98$ & $201.76 \pm 34.36$ \\
Day 90 & $6.97 \pm 0.86$ & $147.24 \pm 29.71$ & $186.12 \pm 35.37$ \\
$\Delta^{\mathrm{a}}$ & 0.61 & 7.82 & 15.64 \\
$p$ value & $0.14^{\mathrm{c}}$ & $0.46^{\mathrm{c}}$ & $0.20^{\mathrm{c}}$ \\
Group II & & & \\
Day 0 & $8.42 \pm 1.27$ & $166.65 \pm 48.06$ & $248.71 \pm 66.84$ \\
Day 90 & $7.49 \pm 1.14$ & $150.59 \pm 41.88$ & $224.24 \pm 61.84$ \\
$\Delta^{\mathrm{a}}$ & 0.93 & 16.06 & 24.47 \\
$\quad$ value & $<0.001^{\mathrm{b}}$ & $0.31^{\mathrm{c}}$ & $0.28^{\mathrm{c}}$ \\
Group III & & & \\
Day 0 & $8.35 \pm 0.96$ & $186.82 \pm 24.47$ & $211.76 \pm 27.56$ \\
Day 90 & $8.41 \pm 0.90$ & $189.65 \pm 24.68$ & $214.12 \pm 26.99$ \\
$\Delta^{\mathrm{a}}$ & -0.06 & 2.83 & 2.36 \\
$\quad p$ value & $0.85^{\mathrm{c}}$ & $0.74^{\mathrm{c}}$ & $0.80^{\mathrm{c}}$ \\
$\Delta$ (Dox vs & $0.32^{\mathrm{b}}$ & $8.24^{\mathrm{b}}$ & $8.83^{\mathrm{b}}$ \\
SRP) & & & \\
$\Delta$ (Dox vs & $0.87^{\mathrm{b}}$ & $13.23^{\mathrm{b}}$ & $22.11^{\mathrm{b}}$ \\
Non) & & & $13.28^{\mathrm{b}}$ \\
$\Delta$ (SRP vs & $0.55^{\mathrm{b}}$ & $4.99^{\mathrm{b}}$ & \\
Non) & & & \\
\hline
\end{tabular}

Values are presented as mean \pm standard deviation

HbA1c, glycated hemoglobin; FPG, fasting plasma glucose; PPG, postprandial glucose

${ }^{\text {b}}$ Statistically significant difference

'Not statistically significant difference

$\Delta^{\mathrm{a}}$ : changes in-between day 90 and day 0

$p$ value: comparison between day 90 and day 0

$\Delta$ (Dox vs SRP): changes in mean differences (day 90 vs day 0 ) between group II and group I

$\Delta$ (Dox vs Non): changes in mean differences (day 90 vs day 0 ) between group II and group III

$\Delta$ (SRP vs Non): changes in mean differences (day 90 vs day 0 ) between group I and group III

it is accepted to be having autoimmune pathophysiology ${ }^{49,50}$ and is usually treated by administrating insulin. Besides, glucose levels in these subjects need to be monitored very steadily and adjusted frequently to prevent hypoglycemic crisis. In addition, the subjects with type $1 \mathrm{DM}$ in general are too young to develop moderate to severe periodontitis. ${ }^{47}$

In the present study, it was chosen to administer systemic doxycycline in patients of group 2 . The reason for selecting doxycycline is its well-documented anticollagenolytic effect and lowering effect on $\mathrm{HbA1c}$ by various authors like Iwamato et al. and Grossi et al. ${ }^{18,26}$ In addition, the extracellular glycation of proteins, which are implicated in many of the long-term complications of diabetes, is also inhibited by tetracycline through the inhibition of nonenzymatic glycosylation..$^{18,26,51}$ Notably, none of the subjects of the present study experienced any adverse effects with the systemic doxycycline. The results of the present study lie in accordance to the study conducted by Gaikwad et al., where a statistical significant difference was observed for all clinical parameters like probing depth (PD), CAL, PI, and GI recorded between baseline and 4 months. However, this study failed to show a statistical significance in improvement of $\mathrm{HbA} 1 \mathrm{c}$ level at the end of follow-up. ${ }^{19}$ 
Probing pocket depth reduction is considered as an important aspect for evaluation of the success of periodontal therapy. In the present study, the subjects were assessed for PPD on day 90 following SRP, as it is suggested that a period of 3 months after therapy is ideal for reassessment though the most appropriate timing for assessment of the healing response is controversial in the literature. ${ }^{52,53}$ The reduction in PPD was found to be highly significant for the doxycycline with SRP group compared to control and SRP alone group. This finding is in accordance to the study conducted by Mubarak et al. stating the reduction of PPD to be highly significant $(p<0.001)$ for doxycycline and SRP group compared to SRP alone at the end of 3, 6, 9, and 12 months follow-up. The results were similar for CAL, PI, GI, TNF alpha levels, and $\mathrm{HbA} 1 \mathrm{c}$ levels. ${ }^{54}$

Fasting plasma glucose and PPG are considered to be vital tests for the diagnosing diabetes, while the $\mathrm{HbA1c}$ value indicates a subject's overall glycemic control in diabetics. HbA1c depicts the mean glucose level in the blood for a period of 2-3 months prior to its measurement. Thus, the temporal gap in-between two evaluations should be at least 2 months apart. ${ }^{55}$

One of the important points noted in the present study is the significant reduction in $\mathrm{HbA1c}$ levels in patients of group II, which received systemic doxycycline in addition to SRP, but not in subjects of group I, which received only SRP. These results are in accordance to the study by Al Mubarak et al., where HbA1c showed significant improvement $(p<0.05)$ only for subjects with $\mathrm{HbA} 1 \mathrm{c} \% \leq 8.8 \%$ within each group. ${ }^{54}$

It may be due to the fact that antimicrobial therapy in addition to SRP pivots its efficacy by reduction of circulating TNF- $a$, which further reduces the levels of insulin and $\mathrm{HbA1c} .^{18,26}$

In the present study, conversely, FPG and PPG were not reduced significantly. This may suggest that HbA1c, FPG, and PPG levels are not correlated. Thereby, $\mathrm{HbA1c}$ value is difficult to predict from the evaluation of FPG and PPG. ${ }^{56}$

A recent systematic review by Santos et al. concludes the addition of systemic antibiotic use with SRP in diabetic patients to provide an additional benefit in terms of reductions in mean pocket depth and mean percentage of bleeding on probing (BoP). This systematic review and meta-analysis included five studies with at least 6-month follow-up to find a significant effect favoring SRP plus antibiotics for reductions in mean PD $(-0.22 \mathrm{~mm}[-0.34,-0.11])$ and mean percentage of $\operatorname{BoP}(4 \%[-7,-1]) .{ }^{57}$

\section{Limitations of the Present Study}

Considering the small sample size and lack of nondiabetic subjects with periodontitis in the present investigation, further studies, possibly in collaboration with an endocrinologist, are required to confirm our findings. Long-term follow-up and more informative outcomes are necessary for better understanding the relationship between type $2 \mathrm{DM}$ and chronic periodontitis. A disadvantage of block randomization is that the allocation of participants may be predictable and result in selection bias when the study groups are unmasked. However, further study involving larger sample size with longer follow-up is required to confirm the findings of the present study. The authors suggest the scope of performing another prospective clinical study on indoor subjects who are under proper medication and diet and directly under the supervision of an endocrinologist.

\section{Conclusion}

The observations indicate an improvement in $\mathrm{HbA1c}, \mathrm{FPG}$, and PPG related with improvement in periodontal health. Adjunctive doxycycline therapy improved the metabolic and periodontal parameters to a statistically significant extent when compared to the periodontal therapy alone.

\section{Clinical Significance}

The prevalence of diabetes as well as periodontitis is increasing nowadays in the world. With treatment of periodontitis, it is found that there is reduction of glycemic level in diabetes. So it is an alert to health professionals about the relation of diabetes and periodontitis and so that they conduct a multidisciplinary treatment.

\section{References}

1. Persson GR. What has ageing to do with periodontal health and disease? Int Dent J 2006;56(4 Suppl 1):240-249. DOI: 10.1111/j.1875595X.2006.tb00108.x.

2. Thornton-Evans $G$, Eke $P$, Wei $L$, et al. Periodontitis among adults aged $\geq 30$ years - United States, 2009-2010. MMWR Suppl 2013;62(3): $129-135$.

3. Mealey BL, Rose LF. Diabetes mellitus and inflammatory periodontal diseases. Curr Opin Endocrinol Diabetes Obes 2008;15(2):135-141. DOI: 10.1097/MED.0b013e3282f824b7.

4. Telgi RL, Tandon V, Tangade PS, et al. Efficacy of nonsurgical periodontal therapy on glycaemic control in type II diabetic patients: a randomized controlled clinical trial. J Periodontal Implant Sci 2013;43(4):177-182. DOI: 10.5051/jpis.2013.43.4.177.

5. Sánchez-Zamora Yl, Rodriguez-Sosa M. The role of MIF in type 1 and type 2 diabetes mellitus. J Diabetes Res 2014;2014:804519. DOI: $10.1155 / 2014 / 804519$.

6. Santacroce L, Carlaio RG, Bottalico L. Does it make sense that diabetes is reciprocally associated with periodontal disease? Endocr Metab Immune Disord Drug Targets 2010;10(1):57-70. DOI: 10.2174/187153010790827975.

7. Taylor GW, Borgnakke WS. Periodontal disease: associations with diabetes, glycemic control and complications. Oral Dis 2008;14(3): 191-203. DOI: 10.1111/j.1601-0825.2008.01442.x.

8. Tsai C, Hayes C, Taylor GW. Glycemic control of type 2 diabetes and severe periodontal disease in the US adult population. Community Dent Oral Epidemiol 2002;30(3):182-192. DOI: 10.1034/j.16000528.2002.300304.x.

9. Soskolne WA, Klinger A. The relationship between periodontal diseases and diabetes: an overview. Ann Periodontol 2001;6(1):91-98. DOI: 10.1902/annals.2001.6.1.91.

10. LöeH. Periodontal disease. The sixth complication of diabetes mellitus. Diabetes Care 1993;16(1):329-334. DOI: 10.2337/diacare.16.1.329.

11. Mirnić J, Djurić M, Predin T, et al. Impact of the level of metabolic control on the non-surgical periodontal therapy outcomes in diabetes mellitus type 2 patients--clinical effects. Srp Arh Celok Lek 2013;141(11-12):738-743. DOI: 10.2298/SARH1312738M.

12. Noack B, Genco RJ, Trevisan M, et al. Periodontal infections contribute to elevated systemic C-reactive protein level. J Periodontol 2001;72(9):1221-1227. DOI: 10.1902/jop.2000.72.9.1221.

13. Mohamed-Ali V, Goodrick S, Rawesh A, et al. Subcutaneous adipose tissue releases interleukin-6, but not tumor necrosis factor-alpha, in vivo. J Clin Endocrinol Metab 1997;82(12):4196-4200. DOI: 10.1210/ jcem.82.12.4450.

14. Natali A, Toschi E, Baldeweg S, et al. Clustering of insulin resistance with vascular dysfunction and low-grade inflammation in type 2 diabetes. Diabetes 2006;55(4):1133-1140. DOI: 10.2337/ diabetes.55.04.06.db05-1076. 
15. Salvi GE, Collins JG, Yalda B, et al. Monocytic TNF alpha secretion patterns in IDDM patients with periodontal diseases. J Clin Periodontol 1997;24(1):8-16. DOI: 10.1111/j.1600-051X.1997.tb01178.x.

16. Mealey BL, Oates TW, American Academy of Periodontology. Diabetes mellitus and periodontal diseases. J Periodontol 2006;77(8): 1289-1303. DOI: 10.1902/jop.2006.050459.

17. Taylor GW. Bidirectional interrelationships between diabetes and periodontal diseases: an epidemiologic perspective. Ann Periodontol 2001;6(1):99-112. DOI: 10.1902/annals.2001.6.1.99.

18. Iwamoto Y, Nishimura F, Nakagawa M, et al. The effect of antimicrobial periodontal treatment on circulating tumor necrosis factor-alpha and glycated hemoglobin level in patients with type 2 diabetes. J Periodontol 2001;72(6):774-778. DOI: 10.1902/jop.2001.72.6.774.

19. Gaikwad SP, Gurav AN, Shete AR, et al. Effect of scaling and root planing combined with systemic doxycycline therapy on glycemic control in diabetes mellitus subjects with chronic generalized periodontitis: a clinical study. J Periodontal Implant Sci 2013;43(2): 79-86. DOI: 10.5051/jpis.2013.43.2.79.

20. Bharti $\mathrm{P}, \mathrm{Katagiri} \mathrm{S}, \mathrm{Nitta} \mathrm{H}$, et al. Periodontal treatment with topical antibiotics improves glycemic control in association with elevated serum adiponectin in patients with type 2 diabetes mellitus. Obes Res Clin Pract 2013;7(2):e129-e138. DOI: 10.1016/j.orcp.2011.11.005.

21. Sakellari D, Goodson JM, Kolokotronis A, et al. Concentration of 3 tetracyclines in plasma, gingival crevice fluid and saliva. J Clin Periodontol 2000;27(1):53-60. DOI: 10.1034/j.1600-051x. 2000.027001053.x

22. Sorsa T, Tjäderhane L, Konttinen $Y T$, et al. Matrix metalloproteinases: contribution to pathogenesis, diagnosis and treatment of periodontal inflammation. Ann Med 2006;38(5):306-321. DOI: 10.1080/07853890600800103.

23. Wang N, Tian X, Chen Y, et al. Low dose doxycycline decreases systemic inflammation and improves glycemic control, lipid profiles, and islet morphology and function in $\mathrm{db} / \mathrm{db}$ mice. Sci Rep 2017;7(1):14707. DOI: 10.1038/s41598-017-14408-7.

24. Silness J, Loe H. Periodontal disease in pregnancy. II. Correlation between oral hygiene and periodontal condtion. Acta Odontol Scand 1964;22(1):121-135. DOI: 10.3109/00016356408993968.

25. Loe $\mathrm{H}$, Silness J. Periodontal disease in pregnancy. I. Prevalence and severity. Acta Odontol Scand 1963;21(6):533-551. DOI: 10.3109/00016356309011240.

26. Grossi SG, Skrepcinski FB, DeCaro T, et al. Treatment of periodontal disease in diabetics reduces glycated hemoglobin. J Periodontol 1997;68(8):713-719. DOI: 10.1902/jop.1997.68.8.713.

27. Salvi GE, Spets-Happonen S, Singer RE, et al. Reconstitution of a hyperinflammatory prostaglandin E2 response to Porphyromonas gingivalis challenge in severe combined immunodeficient mice. J Periodontol 2005;76(1):16-21. DOI: 10.1902/jop.2005.76.1.16.

28. Frantzis TG, Reeve CM, Brown AL. The ultrastructure of capillary basement membranes in the attached gingiva of diabetic and nondiabetic patients with periodontal disease. J Periodontol 1971;42(7):406-411. DOI: 10.1902/jop.1971.42.7.406.

29. Listgarten MA, Ricker FH, Laster $L$, et al. Vascular basement lamina thickness in the normal and inflamed gingiva of diabetics and non-diabetics. J Periodontol 1974;45(9):676-684. DOI: 10.1902/ jop.1974.45.9.676.

30. Seppälä B, Sorsa T, Ainamo J. Morphometric analysis of cellular and vascular changes in gingival connective tissue in long-term insulindependent diabetes. J Periodontol 1997;68(12):1237-1245. DOI: 10.1902/jop.1997.68.12.1237.

31. Ramamurthy NS, Golub LM. Diabetes increases collagenase activity in extracts of rat gingiva and skin. J Periodontal Res 1983;18(1):23-30. DOI: 10.1111/j.1600-0765.1983.tb00331.x.

32. Cianciola LJ, Park BH, BruckE, et al. Prevalence of periodontal disease in insulin-dependent diabetes mellitus (juvenile diabetes). J Am Dent Assoc 1982;104(5):653-660. DOI: 10.14219/jada.archive.1982.0240.

33. Taylor GW, Burt BA, Becker MP, et al. Non-insulin dependent diabetes mellitus and alveolar bone loss progression over 2 years. J Periodontol 1998;69(1):76-83. DOI: 10.1902/jop.1998.69.1.76.
34. Nelson RG, Shlossman M, Budding LM, et al. Periodontal disease and NIDDM in Pima Indians. Diabetes Care 1990;13(8):836-840. DOI: 10.2337/diacare.13.8.836.

35. Kiran M, Arpak N, Unsal E, et al. The effect of improved periodontal health on metabolic control in type 2 diabetes mellitus. J Clin Periodontol 2005;32(3):266-272. DOI: 10.1111/j.1600-051X. 2005.00658.x.

36. Stewart JE, Wager KA, Friedlander AH, et al. The effect of periodontal treatment on glycemic control in patients with type 2 diabetes mellitus. J Clin Periodontol 2001;28(4):306-310. DOI: 10.1034/j.1600051x.2001.028004306.x.

37. Rodrigues DC, Taba MJ, Novaes ABJ, et al. Effect of non-surgical periodontal therapy on glycemic control in patients with type 2 diabetes mellitus. J Periodontol 2003;74(9):1361-1367. DOI: 10.1902/ jop.2003.74.9.1361.

38. Promsudthi A, Pimapansri S, Deerochanawong $C$, et al. The effect of periodontal therapy on uncontrolled type 2 diabetes mellitus in older subjects. Oral Dis 2005;11(5):293-298. DOI: 10.1111/j.16010825.2005.01119.x.

39. Faria-Almeida R, Navarro A, Bascones A. Clinical and metabolic changes after conventional treatment of type 2 diabetic patients with chronic periodontitis. J Periodontol 2006;77(4):591-598. DOI: 10.1902/jop.2006.050084.

40. Madden TE, Herriges B, Boyd LD, et al. Alterations in HbA1c following minimal or enhanced non-surgical, non-antibiotic treatment of gingivitis or mild periodontitis in type 2 diabetic patients: a pilot trial. J Contemp Dent Pract 2008;9(5):9-16. DOI: 10.5005 /jcdp-9-5-9.

41. O'Connell PAA, Taba M, Nomizo A, et al. Effects of periodontal therapy on glycemic control and inflammatory markers. J Periodontol 2008;79(5):774-783. DOI: 10.1902/jop.2008.070250.

42. Al-Zahrani MS, Bamshmous SO, Alhassani AA, et al. Short-term effects of photodynamic therapy on periodontal status and glycemic control of patients with diabetes. J Periodontol 2009;80(10):1568-1573. DOI: 10.1902/jop.2009.090206.

43. Lee H-K, Choi S-H, Won KC, et al. The effect of intensive oral hygiene care on gingivitis and periodontal destruction in type 2 diabetic patients. Yonsei Med J 2009;50(4):529-536. DOI: 10.3349/ ymj.2009.50.4.529.

44. Seppälä B, Ainamo J. A site-by-site follow-up study on the effect of controlled versus poorly controlled insulin-dependent diabetes mellitus. J Clin Periodontol 1994;21(3):161-165. DOI: 10.1111/j.1600051X.1994.tb00297.x.

45. Aldridge JP, Lester V, Watts TL, et al. Single-blind studies of the effects of improved periodontal health on metabolic control in type 1 diabetes mellitus. J Clin Periodontol 1995;22(4):271-275. DOI: 10.1111/j.1600-051X.1995.tb00147.x.

46. Westfelt $\mathrm{E}$, Rylander $\mathrm{H}$, Blohmé $\mathrm{G}$, et al. The effect of periodontal therapy in diabetics. Results after 5 years. J Clin Periodontol 1996;23(2):92-100. DOI: 10.1111/j.1600-051X.1996.tb00540.x.

47. Janket S-J, Wightman $A$, Baird $A E$, et al. Does periodontal treatment improve glycemic control in diabetic patients? A meta-analysis of intervention studies. J Dent Res 2005;84(12):1154-1159. DOI: $10.1177 / 154405910508401212$.

48. da Cruz GA, de Toledo S, Sallum EA, et al. Clinical and laboratory evaluations of non-surgical periodontal treatment in subjects with diabetes mellitus. J Periodontol 2008;79(7):1150-1157. DOI: 10.1902/ jop.2008.070503.

49. Yoon JW. Role of viruses in the pathogenesis of IDDM. Ann Med 1991;23(4):437-445. DOI: 10.3109/07853899109148087.

50. Szopa TM, Titchener PA, Portwood ND, et al. Diabetes mellitus due to viruses--some recent developments. Diabetologia 1993;36(8): 687-695. DOI: 10.1007/BF00401138.

51. Ryan ME, Ramamurthy NS, Golub LM. Tetracyclines inhibit protein glycation in experimental diabetes. Adv Dent Res 1998;12(2):152-158. DOI: $10.1177 / 08959374980120011201$.

52. Morrison EC, Ramfjord SP, Hill RW. Short-term effects of initial, nonsurgical periodontal treatment (hygienic phase). J Clin 
Periodontol 1980;7(3):199-211. DOI: 10.1111/j.1600-051X.1980. tb01963.x.

53. Lowenguth RA, Greenstein G. Clinical and microbiological response to nonsurgical mechanical periodontal therapy. Periodontol 2000 1995;9(1):14-22. DOI: 10.1111/j.1600-0757.1995.tb00052.x.

54. Al Mubarak S, Rass MA, Alsuwyed A, et al. A new paradigm between mechanical scaling and root planing combined with adjunctive chemotherapy for glycated hemoglobin improvement in diabetics. Int J Diabetes Mellitus 2010;2(3):158-164. DOI: 10.1016/ j.ijdm.2010.08.006.
55. American Diabetes Association. Diagnosis and classification of diabetes mellitus. Diabetes Care 2010;33(Suppl 1):S62-S69. DOI: 10.2337/dc10-S062.

56. Bouma M, Dekker JH, de Sonnaville JJ, et al. How valid is fasting plasma glucose as a parameter of glycemic control in non-insulinusing patients with type 2 diabetes? Diabetes Care 1999;22(6): 904-907. DOI: 10.2337/diacare.22.6.904.

57. Santos CM, Lira-Junior R, Fischer RG, et al. Systemic antibiotics in periodontal treatment of diabetic patients: a systematic review. PLoS One 2015;10(12):e0145262. DOI: 10.1371/journal.pone.0145262. 